\title{
Investigative Journalism in Malaysia: The Battle Between Outside and Inside Newsroom Challenges
}

\author{
Ismail Adibah ${ }^{1, *}$, Ahmad Mohd. Khairie ${ }^{2}$, and Mustaffa $\mathrm{Che} \mathrm{Su}^{3}$ \\ ${ }^{1,2,3}$ Universiti Utara Malaysia, 06000 Sintok, Kedah, Malaysia.
}

\begin{abstract}
Investigative journalism originated in Western countries but the practice has spread throughout the world, including countries with different political and media environment. Current literature is dominated by Western perspectives, focusing mainly on the developed countries viewpoint. This study is exploring a controlled media environment, focusing on Eastern developing country. This research explores media practitioners' perception on challenges of practicing investigative journalism in Malaysia. In-depth interviews were used in this research. A total of 16 informants were interviewed. Data was examined using thematic analysis. It was found that Malaysian media practitioners acknowledged six outside challenges and eight inside the newsroom challenges. The study concludes that challenges in controlled media environment revolve around press freedom issue and inside the newsroom struggles due to different editorial orientation on the value of investigative journalism.
\end{abstract}

\section{Introduction}

Investigative journalism plays an important role as watchdog of the government and corporate world, for the benefit of the public. This highly respected kind of journalism has been exposing secrets, scandals and wrongdoings for more than two centuries. Although investigative journalism is being practiced around the world, much research has been done from the Western developed countries viewpoint. This study attempts to enhance the literature by exploring investigative journalism from a different perspective, of an Eastern developing country. Investigative journalism has often been more celebrated than practiced because there are many obstacles that hinder the journalists from practicing it. The challenges face by investigative reporters "came as much from the outside as within" [1]. Therefore, current research specifically focuses on understanding the outside and within newsroom challenges faced by investigative reporters in Malaysia.

* Corresponding author: adibah@uum.edu.my 


\section{The outside and inside battle}

Investigative journalism practitioners have to face challenges both outside and within their newsroom. The outside challenge involves the unambiguous logic that wrongdoing is difficult to uncover [2] because someone is trying to conceal it. This concealment involves not only the wrongdoers, but sometimes involves the authorities that cover up information on the basis of national security or harmony. For example, Lavrov [3] alleged that in Ukraine, if journalists' investigation involves people in power, the government system would work impeccably to conceal it. He revealed that law enforcement officers even go to the extent of destroying the evidence and denying its existence. Without evidence and supporting documents, proving a story and getting it published is difficult. In the United States, Feldstein [4] remarked that exposing secrets is getting tougher because the government erected a wall of secrecy after the 9/11 terrorist attacks.

Adding to the outside challenges is the laws controlling the media $[2,3,5,6,7]$. These laws have been seen as responsible for stifling investigative journalism. Britain, Armenia, Poland, Ukraine and Ireland were among those countries where problems with libel laws are evident $[8,3,9]$. This outside challenge has triggered inside challenges including forcing reporters to exercise self-censorship, sub-editors rewrite to tone down controversial issues, and news editors try to turn a deaf ear to the people's grievances [5]. The risk involved in practicing investigative journalism is another challenge discouraging journalists to pursue investigative reporting [4,10,11,12]. Anderson and Benjaminson [12] have written that investigative journalism is the most risky pursuit in the media. Reporters actually have to face risks before they start an investigation as well as during and after they have finished because people are trying from every angle to stop investigative reporters from bringing the truth to the public.

On the other hand, media ownership concentrations were seen as a challenge within newsroom $[4,13,14,11,15,16,17,18,19]$. It involves closing of small newspapers, corporate buyouts and media mergers. These developments have increased the concern that too few control too much [16]. Tanner [15] posits that "increasingly media outlets are falling into the hands of people with no tradition of journalism, who see journalism as an extension of marketing and do not have any respect for independent journalism". Moreover, concentrated ownership leads to reduced opportunities for journalists to get their investigative article published because the company's shares are mostly own by people with power and authority like the government. Therefore, media organisations will avoid publishing something that will tarnish their owner's reputation. Media owners also give advertisers and sponsors unwarranted influence over news agendas and even the composition of individual news items [14,11]. De Burgh [17] supported this claim by saying that the concentration of media ownership has had a profound impact on the content of the print and broadcast media and on the very nature of investigative journalism itself. For a corporation that is profit oriented, commercials and advertising space are their first priority, not the news. There is not enough space left for investigative stories to fit in. Another syndrome brought about by ownership is the limited opportunity to publish a story when the organisation's investigative reporters are working for the subsidiary of a large media corporation. This is because, when the top management decides not to publish the story, investigative journalists have no other places to turn to.

Scholars also argued that investigative reports have become expensive to produce $[4,2$, $11,10,7]$ since most investigative reporters are senior reporters with high pay. Staffing pressure is another challenge for editors because investigative journalism takes time and very risky. Editors allow reporters to do investigative reporting only in their free time thus, journalists do not have enough time to do research. They are pressured to write about local affairs, telling people what happens throughout the day. When no resources are offered to 
support these journalists, it is like telling reporters not to do investigative reporting at all. Hargreaves [14] posits that journalists and even editors have become overly dependent on press release. This has become an acceptable culture in news organisations [20]. Feldstein [13] added that journalists are not only touched by partisanship but also by stenography. They just report the news and do not analyse the information and write a more meaningful report. Last but not least, the media is increasingly putting more emphasis on infotainment [4]. It has brought with it the syndrome of tabloidisation or what Franklin [21] called as "broadloid journalism". This is the combination of broadsheet and tabloid. According to Franklin, there has been a general retreat from investigative journalism and the reporting of hard news stories. Broadsheet front pages now mimic those of the tabloids with similar banner headlines, alternative and funny headlines, large print, less text, shorter words, coloured and bigger pictures.

Although significant, these outside and inside newsroom challenges have been analysed from developed Western countries viewpoint. This research will examine these challenges from a different viewpoint involving a different media landscape. Using qualitative indepth interview technique, this research interviews 16 media practitioners who have experience in investigative journalism to gather a holistic and in-depth understanding on challenges they are facing in practicing investigative journalism in Malaysia. All interviews were transcribed and analysed using thematic analysis, with the help of NVivo software. Informants were identified as Informant 01 to Informant 16 to conceal their identity.

\section{Findings and discussions}

Interviews yielded two themes of challenges separating the outside and inside challenges faced by investigative journalism practitioners in Malaysia. For outside challenges, six attributes were mentioned by informants which are lawsuits, information availability, issues availability, seeking the truth, weak enforcement and low impact. For inside the newsroom challenges, informants mentioned eight attributes which are journalism skills, culture differences, time, risk, cost, human resources, attitude and media sustainability. Four out of six outside the newsroom challenges mentioned by informants involve the issue of press freedom which has a very close link to government control of the media. The attributed are lawsuits, information availability, seeking the truth and issues availability. Malaysian media practitioners regarded press freedom parameters as values guiding their practice of investigative journalism. This makes it the biggest challenge to conduct investigative journalism as they are already accustomed to the parameters as their boundary. It makes issues availability, information availability and seeking for the truth very challenging tasks.

In a close media system like Malaysia's, it is hard to find whistle blowers since there is no law protecting them. They might need to risk their job by blowing the whistle, where not many are willing to do so. Without whistle blowers, it is a challenging task to find an issue to investigate or a lead to follow up on. Informants also admitted that only a strong reputation will attract whistle blowers. Hence, not many reporters are eligible, especially young reporters who do not have many connections. Other than whistle blowers, reporters have to count on their instinct and inquisitive nature to snoop for issues to investigate.

The second challenge that comes after finding an issue to investigate is getting the information to support the story. According to informants, having a good reputation with sources sometimes helps but it is still hard to get detailed information especially from government agencies. They have to go through much red tape and bureaucracy, even if they are working for the mainstream media which usually publishes positive information about the government in any case. These are the consequences of press freedom parameters in Malaysia which has become accustomed in daily practice. Government officials are so 
afraid to give information to reporters without clearance from their managers or superiors. This is a big challenge for reporters because they have deadlines to meet.

The third consequence of press freedom parameters in Malaysia is reporters' reliance on online information. Since they have limited access to official sources, reporters turned to the Internet which provides access to the information highway. However, this is not the answer to their information hunger because it is hard to determine the credibility of online information, making finding the truth more challenging than ever. This leads to less confidence in publishing investigative reports because reporters are afraid that they will be sued if they cannot verify their facts. It is also a setback for media organisations to publish investigative reports since they have to bear all the costs if they lose the case, which will also tarnish their credibility and reputation.

Apart from press freedom threats, media organisations also struggle with low impact of investigative reports and weak enforcement from authorities on the consequences of an exposé. These challenges are tight corners for media organisations to either investigate or drop. With the public now turning to the online media, so do advertisers. Therefore, the media cannot allocate large spaces for investigative reports which might not attract public attention. They have to find material that will attract an audience and at the same time pull advertisers. This is the reason why media are publishing more sensational, light, human interest stories compared to serious, heavy and long investigative reports. Audience attitude towards investigative reports has also changed the media organisation, and editors' and reporters' perceptions on practicing investigative journalism. It's worsening when reporters' hard work does not draw authorities' attention. Some informants expressed their disappointment when their reports do bring about a policy change but because of weak enforcement, the wrongdoing continues to be done months after its exposure.

The above mentioned outside challenges will trigger inside the newsroom challenge when it demotivates journalists to pursue investigative journalism. They lost their passion to look for issues, investigate and exposé important public matters. Added with human resource shortage, investigative journalism has been given the back seat where reporters were given daily assignments. Investigative reporting can only be done during their free time. Since investigations can take a very long time to complete, most media organisations do not have the budget to pay journalists who cannot produce stories on a daily basis. Much worse, most good investigative reporters are senior reporters with high salaries. Hence, it hinders the production of investigative reports. In relation to press freedom, reporters require a lot of time to investigate and acquire information from appropriate sources. However, editors are not patient. This time-consuming factor is another big challenge in practicing investigative journalism in Malaysia. Lack of journalism skills adds to the pressure. According to informants who are editors, reporters do not have the requisite skills to sniff for issues. In the current media environment in Malaysia, this is a much needed skill. In addition, reporters are lacking information searching skills. They are more of reporter who report, not journalist who can interpret and elaborate information into something more meaningful to their readers. Writing an investigative report with a closed mind is almost impossible. Editors interviewed in this research also expressed their disappointment in young reporters who are technologically 'savvy' but do not use their skills to search for information. CAR and CAIR are not being utilised properly by Malaysian reporters.

All in all, challenges facing the practice of investigative journalism in Malaysia come from outside and inside media organisation, where some are under their control like human resources, cost, and journalism skills while others like press freedom and media sustainability are beyond their control. However, there are always hope because these situation are not static, there are instead evolving and offering a few bright prospects for investigative journalism to prosper. 


\section{References}

1. Johnston, D. C. The best of times, the worst of times for investigative journalism in the US. In J. Mair, J. \& R.L. Keeble., Investigative journalism: Dead or alive? United Kingdom: Abramis Academic Publishing. 137-150 (2011).

2. Greenwald, Marilyn, \& Joseph Bernt. The big chill: investigative reporting in the current media environment. Ames: Iowa State University Press. (2000).

3. Lavrov, V. Libel laws pose obstacles to Ukraine's investigative journalists. Nieman Reports, 65(1), 19 (2011).

4. Feldstein, M. The challenges and opportunities of 21st century muckraking. Nieman Reports, Summer. 50-53 (2009).

5. Lent, J. A. Restructuring of mass media in Malaysia and Singapore - Pounding in the coffin nails? Bulletin of Concerned Asian Scholars, 16, 4 (1984).

6. Stapenhurst, R. The media's role in curbing corruption. Washington: World Bank Institute. (2000).

7. Willis, J. The human journalist: Reporters, perspectives and emotions. United States of America: Greenwood Publishing Group. (2003).

8. Page, B. British Journalism Review, 21, 1, (2010).

9. Seitz, J. British libel law: Its ripple effect on journalists worldwide. Nieman Reports. Spring, 65 (1), 21 (2011).

10. Houston, B. IRE Journal, 27(6), 4 (2004).

11. Haxton, N. The Death of Investigative Journalism? In Tanner (Ed.) Journalism: Investigation and Research. Malaysia: Pearson Education Australia. 20-36 (2002).

12. Anderson, D., \& Benjaminson, P. Investigative reporting. Bloomington: Indiana University Press. (1976).

13. Feldstein, M. A muckraking model: Investigative reporting cycles in American history. Press/Politics, 11(2), 1- 16 (2006).

14. Hargreaves, I. Journalism truth or dare? Oxford: Oxford University Press. (2003).

15. Tanner, S. Journalism: Investigation and Research. Malaysia: Pearson Education Australia. (2002).

16. Daniel D.K. Best of times and worst of times: Investigative reporting in postWatergate America. In Greenwald, M.S \& Bernt, J. (Eds.), The Big Chill, United States of America: Iowa State University Press. 11-33 (2000).

17. De Burgh, H. New media and investigative journalists in China. In J. Mair \& R.L. Keeble, (Eds.), Investigative journalism: Dead or alive? United Kingdom: Abramis Academic Publishing. 171-181 (2011).

18. Fleming, C. Journalism and new technology. In Hugo de Burgh (Ed.), Investigative journalism: Context and practice. London: Routledge. 169-185 (2000).

19. Waisbord, S. Watchdog journalism in South America: News, accountability, and democracy. New York: Columbia University Press. (2000).

20. Waterford J. The Editor's Position. In S. Tanner, Journalism: Investigation and research. Malaysia: Pearson Education Australia. 37-47 (2002).

21. Franklin, B. Newszak and news media. London: Arnold. (1997). 